\title{
Lewis phenotypes, leisure time physical activity, and risk of ischaemic heart disease: an 11 year follow up in the Copenhagen male study
}

\author{
H O Hein, P Suadicani, F Gyntelberg
}

\begin{abstract}
Objective-To test the hypothesis that the predictive value for risk of fatal ischaemic heart disease associated with Lewis phenotypes depends on the level of leisure time physical activity.

Design-Prospective study controlling for alcohol, tobacco, serum cotinine, blood pressure, body mass index, serum lipids, work related physical activity, and social class.

Setting-The Copenhagen male study, Denmark.

Subjects-2826 white men aged 53-75 years without overt cardiovascular disease; 266 (9.4\%) had the Le $(a-b-)$ phenotype.

Main outcome measure-Incidence of death from ischaemic heart disease during 11 years. Results-107 men died of ischaemic heart disease. Among men with a low level of leisure time physical activity ( $\leqslant 4$ hours/week moderate or $\leqslant 2$ hours/week more vigorous activity), being $\mathrm{Le}(\mathrm{a}-\mathrm{b}-)$ was associated with an increased risk of having a fatal ischaemic heart disease event compared with men with other Lewis phenotypes (relative risk (RR) 2.7, 95\% confidence interval (CI) 1.4 to $5.2 ; \mathrm{p}<0.01$ ). Among men with a high level of leisure time physical activity, the $\mathrm{RR}$ associated with being $\mathrm{Le}(\mathrm{a}-\mathrm{b}-)$ was 1.3 (95\% CI 0.5 to 3.1 ; NS). Compared with all other alternatives tested, being $\operatorname{Le}(\mathrm{a}-\mathrm{b}-)$ and having a low level of leisure time physical activity was associated with an RR of 3.2 (95\% CI 1.7 to $5.8 ; \mathrm{p}<0.001)$. As a point estimate and adjusted for confounding variables, among men with low leisure time physical activity the attributable risk associated with $\operatorname{Le}(\mathrm{a}-\mathrm{b}-)$ was $12 \%$-that is, assuming that all sedentary men had phenotypes other than $\mathrm{Le}(\mathrm{a}-\mathrm{b}-), 12 \%$ of all fatal ischaemic heart disease events would not have occurred. The corresponding point estimate among those more active was $2 \%$.

Conclusions-The excess risk of fatal ischaemic heart disease in middle aged and elderly men with the $\mathrm{Le}(\mathrm{a}-\mathrm{b}-)$ phenotype is strongly modified by leisure time physical activity. Public health and clinical implications may be important in populations with a predominantly sedentary lifestyle and in a high proportion of men with the Le $(\mathrm{a}-\mathrm{b}-)$ phenotype.

(Heart 2001;85:159-164)
\end{abstract}

Keywords: genetics; ischaemic heart disease; risk factors

Lewis is regarded as one of the major blood groups. ${ }^{12}$ In adult white people, three phenotypes dominate: $\operatorname{Le}(\mathrm{a}-\mathrm{b}-)$, $\operatorname{Le}(\mathrm{a}+\mathrm{b}-)$, and $\mathrm{Le}(\mathrm{a}-\mathrm{b}+)$. The phenotype expression is determined by two genetic systems closely related on the short arm of chromosome 19: the Lewis genes Le and le, and the secretor genes, Se and se. The gene product consists of various fucosyl transferases which are adsorbed from tissue liquids to cell surfaces. ${ }^{12}$

It has been shown that, compared with other phenotypes, men with the Lewis blood group phenotype Le $(a-b-)$ have a twofold higher prevalence of ischaemic heart disease ${ }^{34}$ and a three- to fourfold higher incidence of fatal ischaemic heart disease. ${ }^{5-7}$ In the white populations of the UK and Scandinavia, about $10 \%$ of individuals belong to the high risk group for ischaemic heart disease, $\mathrm{Le}(\mathrm{a}-\mathrm{b}-)$. However, there are large ethnic variations in the distribution of Lewis phenotypes, ${ }^{8}$ indicating that the population attributable risk associated with this genetic trait may vary greatly.

At least two ischaemic heart disease risk factors separate $\operatorname{Le}(a-b-)$ men from others: they have a higher body mass index $(\mathrm{BMI})^{39}$ and a higher serum triglyceride concentration. ${ }^{34}$ Many epidemiological studies and clinical trials have shown that leisure time physical activity has a beneficial effect on these and other risk factors for ischaemic heart disease. ${ }^{10-15}$

Most observational epidemiological studies have shown an inverse association between leisure time physical activity and the risk of ischaemic heart disease. ${ }^{16}$ Accordingly, as $\mathrm{Le}(\mathrm{a}-\mathrm{b}-)$ men have an excess risk of ischaemic heart disease compared with others, and a risk factor profile that may be improved by physical activity, increased activity should be more beneficial in men with this phenotype than in men with the other Lewis phenotypes as a means of reducing their risk of ischaemic heart disease. We tested the hypothesis that the predictive value for risk of fatal ischaemic heart disease associated with Lewis phenotypes depends on the level of leisure time physical activity.

\section{Methods}

The Copenhagen male study (CMS) was set up in 1970 as a prospective cardiovascular study. ${ }^{17}$ The men came from 14 larger work places in Copenhagen, and all employed white men (6125 men aged 40-59 years (mean 48 years)) were invited to participate, from the 
managing director to the porter. In all, 5249 men participated $(87 \%)$.

In 1985-86 a new baseline was established and used for this study. All survivors from the 1970 study were traced by means of the civil registration system. Between June 1985 and June 1986, all survivors from the original cohort (4505 excluding 34 emigrants) were invited to take part in this new study; 3387 men $(75 \%)$ participated and gave informed consent. Their mean age was 63 years (range 53-74 years).

Each subject was interviewed by a physician $(\mathrm{HOH})$ about a previously completed questionnaire and then examined, with measurements of height, body weight, blood pressure, and an ECG recording. A venous blood sample was taken after the subject had fasted for at least 12 hours, for measurements of Lewis phenotypes, serum lipids, and serum cotinine.

Lewis typing was carried out on fresh samples of washed red cell suspensions using a saline haemagglutination technique in test tubes with monoclonal $\mathrm{a}$ and $\mathrm{b}$ antibodies (Seraclone, Biotest, Dreieich, Germany). One drop of antibody was mixed with one drop of $5 \%$ erythrocyte suspension and read macroscopically. The Lewis phenotype distribution was: Le(a-b-) 266 (9.4\%); Le(a+b-) 549 (19.4\%); and Le $(\mathrm{a}-\mathrm{b}+) 2011(71.2 \%)$. Differences in risk factor characteristics and risk of ischaemic heart disease were small and not significant between men with $\operatorname{Le}(\mathrm{a}+\mathrm{b}-)$ and $\operatorname{Le}(\mathrm{a}-\mathrm{b}+)$; accordingly, these phenotypes were pooled for the analyses and presentation of results.

Leisure time physical activity was assessed from one of the questions in the questionnaire:

Which description most precisely covers your pattern of leisure time physical activity?

(1) You are almost entirely sedentary or perform light leisure time physical activity less than two hours a week.

(2) You perform light leisure time physical activity two to four hours a week.

(3) You perform light leisure time physical activity more than four hours a week or more vigorous activity two to four hours a week.

(4) You perform highly vigorous leisure time physical activity more than four hours a week or regular exercise or competitive sports several times a week.

Owing to the relatively small number of fatal end points and as differences in risk were small and not significant, for analytical purposes activity groups 3 and 4 were pooled and are referred to as the "high" leisure time physical activity group, while groups 1 and 2 were pooled as the "low" activity group.

The men classified themselves as never having smoked, as being a previous smoker, or as being a current smoker. Current tobacco smoking was calculated from information about the number of cigarettes, cheroots, cigars, or the weight of pipe tobacco smoked daily. One cigarette was taken as equivalent to $1 \mathrm{~g}$ of tobacco, one cheroot as $3 \mathrm{~g}$, and one cigar as $4 \mathrm{~g}$. As previously estimated by means of measurements of serum cotinine, the validity of tobacco reporting was high. ${ }^{18}$

Total weekly use of alcohol was calculated from questionnaire items about average use on weekdays and at weekends. Intakes of beer, wine, and spirits were reported separately. One drink corresponded to 10-12 g of ethanol. The men reported on whether they took medicine on a regular basis, on their self assessed state of health, and on whether they had non-insulin dependent diabetes mellitus (NIDDM). Self reported cancer history was accepted if verified by the National Cancer Register. This register was established 1943 and was the first of all cancer registers; its validity is very high. ${ }^{19}$

Fasting concentrations of total cholesterol, high density lipoprotein (HDL) cholesterol, and triglyceride were determined using standardised methods. ${ }^{20-23}$ It has previously been shown in the Copenhagen male study that a triglyceride concentration within the range of 1.6 to $2.5 \mathrm{mmol} / 1$ is associated with a high risk of ischaemic heart disease. ${ }^{24}$ For analytical purposes triglyceride was therefore entered into the analyses as a dichotomous variable, with subjects classified as being within this range or not. Serum low density lipoprotein (LDL) cholesterol was calculated indirectly using Friedewald's formula. ${ }^{25}$ This formula performs inadequately with a triglyceride concentration above $4 \mathrm{mmol} / 1$. Less than $2 \%$ of the men had values above this and these were included in the study; whether or not this group was excluded from the analyses had no influence on the results presented.

Blood pressure was measured in the right arm with the subject seated, using a manometer developed by the London School of Hygiene and Tropical Medicine. ${ }^{26}$ Hypertension was defined as being on antihypertensive treatment or having a systolic blood pressure of $\geqslant 150 \mathrm{~mm} \mathrm{Hg}$ and a diastolic blood pressure of $\geqslant 100 \mathrm{~mm} \mathrm{Hg}$. Body mass index (BMI) was calculated as weight in $\mathrm{kg}$ divided by height in $\mathrm{m}^{2}$.

A resting ECG with 12 standard leads was recorded. Coding was done according to the Minnesota code. ${ }^{27}$ Changes associated with an increased risk of an ischaemic heart disease event during the follow up period are presented.

The cohort was subdivided into five social classes using a modification of a system by Svalastoga ${ }^{28}$ based on the level of education and the job profile. Men in social class I were predominantly academics and well educated administrators or executives; men in social class $\mathrm{V}$ were unskilled and semiskilled workers.

Men without overt cardiovascular disease were eligible for the prospective study; thus we excluded men who at baseline had a history of acute myocardial infarction, angina pectoris, stroke, or intermittent claudication. We checked the hospital records of all subjects who reported admission to a hospital before the start of the study because of acute myocardial infarction. The diagnosis was accepted if at least two of the following symptoms or signs were recorded: retrosternal pain lasting more than 20 minutes, typical serial ECG changes in more than two ECGs, and an acute increase of 
Table 1 Characteristics of men with different Lewis phenotypes

\begin{tabular}{|c|c|c|}
\hline Variable & $\begin{array}{l}\operatorname{Le}(a-b-) \\
(n=266)\end{array}$ & $\begin{array}{l}\operatorname{Le}(a+b-) / \operatorname{Le}(a-b+) \\
(n=2560)\end{array}$ \\
\hline \multicolumn{3}{|l|}{ Serum lipids } \\
\hline LDL cholesterol (mmol/l) & $4.49(1.01)$ & $4.44(1.00)$ \\
\hline HDL cholesterol (mmol/l) & $1.32(0.36)$ & $1.36(0.35)$ \\
\hline Triglyceride $(\mathrm{mmol} / \mathrm{l})$ & $1.65(1.22)$ & $1.52(0.84)^{\star \star \star}$ \\
\hline \multicolumn{3}{|l|}{ Lifestyle factors } \\
\hline Low leisure time physical activity (n (\%)) & $125(47)$ & $1195(47)$ \\
\hline Low work related physical activity (n (\%)) & $234(89)$ & $2247(88)$ \\
\hline Alcohol use (beverages/week) & $18.9(14.8)$ & $17.7(14.0)$ \\
\hline Smokers $(\mathrm{n}(\%))$ & $138(52)$ & $1304(51)$ \\
\hline Tobacco use (g/day) & $16.9(9.1)$ & $16.5(10.8)$ \\
\hline \multicolumn{3}{|l|}{ Clinical/paraclinical variables } \\
\hline Body mass index $\left(\mathrm{kg} / \mathrm{m}^{2}\right)$ & $26.1(3.5)$ & $25.6(3.3)^{\star}$ \\
\hline Systolic blood pressure $(\mathrm{mm} \mathrm{Hg})$ & $120(15)$ & $121(17)$ \\
\hline Diastolic blood pressure ( $\mathrm{mm} \mathrm{Hg}$ ) & $72(11)$ & $73(12)$ \\
\hline Hypertension (n (\%)) & $34(13)$ & $286(11)$ \\
\hline \multicolumn{3}{|l|}{ Health indices } \\
\hline $\operatorname{NIDDM}(\mathrm{n}(\%))$ & $7(3)$ & $45(2)$ \\
\hline History of cancer (n (\%)) & $22(8)$ & $176(7)$ \\
\hline Regular use of medicines (n (\%)) & $85(32)$ & $788(31)$ \\
\hline Self assessed good health (n (\%)) & $148(56)$ & $1445(57)$ \\
\hline Unverified Rose questionnaire angina pectoris (n (\%)) & $3(1)$ & $42(2)$ \\
\hline Unverified intermittent claudication (n (\%)) & $4(2)$ & $25(1)$ \\
\hline \multicolumn{3}{|l|}{ ECG changes } \\
\hline High amplitude $\mathrm{R}$ wave (n (\%)) & $16(6)$ & $110(4)$ \\
\hline ST depression (n (\%) & $13(5)$ & $111(4)$ \\
\hline T wave abnormalities (n (\%)) & $21(8)$ & $201(8)$ \\
\hline \multicolumn{3}{|l|}{ Sociodemographic factors } \\
\hline Low social class (social class IV or V) (n (\%)) & $139(52)$ & $1278(50)$ \\
\hline Age (years) & $62.8(5.2)$ & $62.8(5.2)$ \\
\hline
\end{tabular}

Values are means (SD) or $\mathrm{n}(\%)$.

${ }^{\star} \mathrm{p}<0.05 ;{ }^{\star \star \star} \mathrm{p}<0.001$ (Student's $t$ test or test for variance homogeneity (triglycerides)).

HDL, high density lipoprotein; LDL, low density lipoprotein; Le, Lewis phenotype; NIDDM, non-insulin dependent diabetes mellitus.

relevant serum enzymes (alanine aminotransferase, lactate dehydrogenase, or creatine phosphokinase $\mathrm{MB}$ ). The questionnaire gave information on angina pectoris according to Rose and colleagues, ${ }^{27}$ and the diagnosis was accepted if the information was confirmed by a physician; intermittent claudication was established from the questionnaire, ${ }^{27}$ as was stroke (verified by a doctor). We excluded 343 men $(10.1 \%)$ because of cardiovascular disease or cardiovascular symptoms, and 218 (6.5\%) because of missing data or conflicting answers. In all, 2826 men were eligible for the incidence study. Among the 343 men excluded because of cardiovascular disease, $214(62.4 \%)$ died during the follow up period; 86 of deaths resulted from ischaemic heart disease - that is, $25.1 \%$ of all deaths in this group, supporting the relevance of the exclusion criteria used.

Mortality and morbidity were recorded between 1985-86 and 31 December 1996 through the Danish Register of Causes of Death and the National Hospital Register. All men who had taken part in the 1985-86 study were traced. We used diagnoses from registers. Diagnoses accepted were codes 410-414 for non-fatal ischaemic heart disease and 410 and 412 for fatal ischaemic heart disease (International Classification of Diseases, 8th revision) and equivalent diagnoses from revision 10, I 20-I 25. The validity of Danish death and disease registers is outstanding, as recently reviewed. ${ }^{29} 30$

The study was approved by the ethics committee for medical research in the County of Copenhagen.
STATISTICAL ANALYSES

We used $\chi^{2}$ and Student's $t$ tests for testing possible differences in characteristics associated with leisure time physical activity level and Lewis phenotypes. Relative risk (RR) with 95\% confidence interval (CI) were estimated from the hazard coefficient for the variable of interest in a Cox's proportional hazards regression model with the maximum likelihood ratio method. ${ }^{31}$ Assumptions for the use of Cox's proportional hazards model were met. The proportional hazards analysis included an interaction term for leisure time physical activity and Lewis phenotypes (as dichotomous variables) to examine whether the interactive effect significantly improved the model fit provided by main effects of the single variables. ${ }^{32}$ In the use of a backward elimination procedure all main effects were adjusted for. A significant interaction term may have one of two major implications: the strength of the association of the risk factor (leisure time physical activity) with the outcome was modified by or dependent on the genetic risk factor $(\operatorname{Le}(a-b-))$; or the strength of genetic risk was modified by or dependent on the presence of the risk factor. The interaction term consisted of the result of a multiplication of the genetic risk factor (coded 1 for present, 0 for absent) and the risk factor (also coded 1 for present and 0 for absent). The interaction term could therefore hold one of two values, 1 meaning the presence of both factors, 0 meaning presence of one of the factors or the absence of both of them. For transparency, regression analyses were also performed, stratified according to leisure time physical activity level and adjusted for age only. All analyses were performed using the SPSS statistical software for Windows. ${ }^{33}{ }^{34}$ For all analyses, a two sided probability value of $\mathrm{p}<0.05$ was taken as significant.

\section{Results}

Table 1 presents the distribution of a large number of cardiovascular risk factors and other health characteristics among $\operatorname{Le}(\mathrm{a}-\mathrm{b}-)$ men and men with other Lewis phenotypes. Interestingly, the proportion of sedentary men was the same among $\operatorname{Le}(\mathrm{a}-\mathrm{b}-)$ men and others, at $47 \%$. Only two risk factors separated $\mathrm{Le}(\mathrm{a}-\mathrm{b}-)$ men from others: a higher BMI and a larger dispersion around the mean of triglyceride. ${ }^{24}$

Table 2 shows the distribution of the same baseline characteristics as presented in table 1 among 1320 men with a low level of leisure time physical activity and 1506 men with a higher level of physical activity. Men with low activity were characterised by lower concentrations of HDL cholesterol and higher concentrations of triglyceride, whereas no differences were found with respect to LDL cholesterol or alcohol consumption. Compared with those more physically active, these men had a higher BMI and a higher prevalence of hypertension and NIDDM, a larger proportion were taking therapeutic drugs, and fewer regarded their health as satisfactory. Resting ECG changes also separated men with a low leisure time physical activity level from those who were more active, with ST depression and $\mathrm{T}$ wave 
Table 2 Characteristics of men with different levels of leisure time physical activity

\begin{tabular}{|c|c|c|}
\hline Characteristic & $\begin{array}{l}\text { Low activity } \\
(n=1320)\end{array}$ & $\begin{array}{l}\text { High activity } \\
(n=1506)\end{array}$ \\
\hline \multicolumn{3}{|l|}{ Serum lipids } \\
\hline LDL cholesterol (mmol/l) & $4.45(1.02)$ & $4.44(0.98)$ \\
\hline HDL cholesterol (mmol/l) & $1.32(0.35)$ & $1.39(0.35)^{\star \star \star}$ \\
\hline Triglyceride $(\mathrm{mmol} / \mathrm{l})$ & $1.65(0.99)$ & $1.43(0.77)^{\star \star \star}$ \\
\hline \multicolumn{3}{|l|}{ Lifestyle factors } \\
\hline Alcohol use (beverages/week) & $18.1(14.7)$ & $17.5(13.5)$ \\
\hline Smokers $(\mathrm{n}(\%))$ & $717(55)$ & $725(48)^{\star \star}$ \\
\hline Tobacco use $(\mathrm{g} / \mathrm{d})$ & $17.3(11.3)$ & $15.9(9.9)^{\star}$ \\
\hline \multicolumn{3}{|l|}{ Clinical/paraclinical variables } \\
\hline Body mass index $\left(\mathrm{kg} / \mathrm{m}^{2}\right)$ & $26.1(3.7)$ & $25.3(3.3)^{\star \star \star}$ \\
\hline Systolic BP (mm Hg) & $122(16)$ & $121(17)$ \\
\hline Diastolic BP (mm Hg) & $73(12)$ & $72(11)^{\star \star}$ \\
\hline Hypertension (n (\%)) & $175(13)$ & $145(10)$ \\
\hline \multicolumn{3}{|l|}{ Health indices } \\
\hline NIDDM (n (\%)) & $37(3)$ & $15(1)^{\star \star \star}$ \\
\hline History of cancer (n (\%)) & $90(7)$ & $108(7)$ \\
\hline Regular use of medicines (n (\%)) & $457(35)$ & $416(28)^{\star \star \star}$ \\
\hline Self assessed good health (n (\%)) & $696(53)$ & $897(60)$ \\
\hline Unverified Rose questionnaire angina pectoris (n (\%)) & $36(3)$ & $9(1)$ \\
\hline Unverified intermittent claudication (n (\%)) & $18(1)$ & $11(1)$ \\
\hline \multicolumn{3}{|l|}{ ECG changes } \\
\hline High amplitude $\mathrm{R}$ wave (n (\%)) & $60(5)$ & $66(4)$ \\
\hline ST depression (n (\%)) & $71(5)$ & $53(4)^{\star}$ \\
\hline $\mathrm{T}$ wave abnormalities (n (\%)) & $125(10)$ & $97(6)^{\star \star}$ \\
\hline \multicolumn{3}{|l|}{ Sociodemographic factors } \\
\hline Low social class (social class IV or V) (n (\%)) & $693(53)$ & $724(48)^{\star}$ \\
\hline Age (years) & $62.4(5.2)$ & $63.1(5.1)$ \\
\hline
\end{tabular}

Values are means $(\mathrm{SD})$ or $\mathrm{n}(\%)$.

${ }^{\star} \mathrm{p}<0.05 ;{ }^{\star \star} \mathrm{p}<0.01 ;{ }^{\star \star \star} \mathrm{p}<0.001$ (Student's $t$ test or $\chi^{2}$ analysis).

Table 3 Crude cumulative incidence (\% (n/total)) of ischaemic heart disease and all cause mortality, with age adjusted relative risk and $95 \%$ confidence interval (CI), during an 11 year follow up according to Lewis phenotype and leisure time physical activity level

\begin{tabular}{|c|c|c|c|}
\hline & \multicolumn{2}{|l|}{ Lewis phenotype } & \multirow{2}{*}{$\begin{array}{l}\text { Relative risk (95\% } \\
C I), \operatorname{Le}(a-b-) v \\
\text { rest }\end{array}$} \\
\hline & $\operatorname{Le}(a-b-)$ & $\begin{array}{l}\operatorname{Le}(a+b-) / \\
\operatorname{Le}(a-b+)\end{array}$ & \\
\hline \multicolumn{4}{|l|}{ Ischaemic heart disease, fatal events } \\
\hline \multicolumn{4}{|l|}{ Low leisure time physical activity } \\
\hline \multicolumn{4}{|l|}{ High leisure time physical activity } \\
\hline level & $4.3 \%(6 / 141)$ & $3.3 \%(45 / 1365)$ & $1.3(0.5$ to 3.1$)$ \\
\hline All men & $6.8 \%(18 / 266)$ & $3.4 \%(89 / 2560)$ & $2.0(1.2 \text { to } 3.4)^{\star \star}$ \\
\hline \multicolumn{4}{|c|}{ Ischaemic heart disease, fatal and non-fatal events } \\
\hline \multicolumn{4}{|c|}{ Low leisure time physical activity } \\
\hline level & $18.4 \%(23 / 125)$ & $15.1 \%(180 / 1195)$ & $1.3(0.8$ to 2.1$)$ \\
\hline \multicolumn{4}{|l|}{ High leisure time physical activity } \\
\hline level & $11.3 \%(16 / 141)$ & $11.4 \%(155 / 1365)$ & $1.1(0.7$ to 1.9$)$ \\
\hline All men & $14.7 \%(39 / 266)$ & $13.1 \%(335 / 2560)$ & $1.2(0.9$ to 1.7$)$ \\
\hline \multicolumn{4}{|l|}{ All cause mortality } \\
\hline \multicolumn{4}{|l|}{ Low leisure time physical activity } \\
\hline \multicolumn{4}{|l|}{ High leisure time physical activity } \\
\hline level & $26.2 \%(37 / 141)$ & $26.0 \%(355 / 1365)$ & $1.0(0.7$ to 1.5$)$ \\
\hline All men & $30.1 \%(80 / 266)$ & $28.1 \%(720 / 2560)$ & $1.1(0.8$ to 1.4$)$ \\
\hline
\end{tabular}

Table 4 Predictors of fatal ischaemic heart disease during 11 years of follow up

\begin{tabular}{ll}
\hline & Relative risk (95\% CI) \\
\hline Age (risk associated with a one year increase) & $1.11(1.08 \text { to } 1.16)^{\star \star \star}$ \\
Le(a-b-) and physically inactive in leisure time $v$ others $\dagger$ & $3.2(1.7 \text { to } 5.8)^{\star \star \star}$ \\
Hypertension treatment $v$ not & $1.8(1.1 \text { to } 2.9)^{\star}$ \\
Triglyceride risk level, 1.6 to $2.5 \mathrm{mmol} / \mathrm{l} v$ others & $1.6(1.1 \text { to } 2.4)^{\star}$ \\
LDL cholesterol (risk associated with a $1 \mathrm{mmol} / \mathrm{l}$ increase) & $1.2(1.0 \text { to } 1.5)^{\star}$ \\
Systolic BP (risk associated with a $10 \mathrm{~mm} \mathrm{Hg}$ increase) & $1.12(1.0 \text { to } 1.23)^{\star}$ \\
\hline
\end{tabular}

Variables are presented according to strength of statistical association with the outcome after multivariable adjustment.

Not included in the final model $(\mathrm{p}>0.10)$ : non-insulin-dependent diabetes mellitus, social class, alcohol consumption, body mass index, smoking, Lewis phenotype (main effect), HDL cholesterol, diastolic blood pressure, leisure time physical activity (main effect).

†Interaction term of Lewis phenotype and leisure time physical activity.

${ }^{\star} \mathrm{p}<0.05 ;{ }^{\star \star \star} \mathrm{p}<0.001$. abnormalities being more common among the least physically active. Finally, a larger proportion of inactive men were from lower social class groups, and they were also on average slightly younger than physically active men.

The average follow up period was 10.5 years. The cumulative incidence of a fatal ischaemic heart disease event was 107 (3.8\%). The cumulative incidence of a first ischaemic heart disease event was $374(13.2 \%) ; 800$ men $(28.3 \%)$ died from all causes of mortality.

Table 3 presents crude cumulative incidence rates of ischaemic heart disease and all causes of mortality, with age adjusted relative risk and 95\% confidence intervals (CI). Among men with a low leisure time physical activity level compared with the others, the relative risk for those with $\mathrm{Le}(\mathrm{a}-\mathrm{b}-)$ was 2.7 (95\% CI 1.4 to 5.2) with fatal ischaemic heart disease as outcome, 1.3 (95\% CI 0.8 to 2.1 ) with all ischaemic heart disease events as outcome, and 1.2 (95\% CI 0.8 to 1.8 ) with all causes of mortality as outcome. Among men with a high leisure time physical activity level, there was a slight but not significantly increased risk of fatal ischaemic heart disease among $\mathrm{Le}(\mathrm{a}-\mathrm{b}-)$ men compared with the others. We tested differences in case fatality rates between $\operatorname{Le}(\mathrm{a}-\mathrm{b}-)$ men and men with other phenotypes. Among Le(a-b-) men, 18 of 39 events $(46.2 \%)$ were fatal; among the others 89 of 335 events $(26.6 \%)$ were fatal; a $\chi^{2}$ test for heterogeneity was highly significant $(p<0.001)$, and the estimated relative risk of suffering a fatal event for $\operatorname{Le}(\mathrm{a}-\mathrm{b}-)$ was 1.7 (95\% CI 1.2 to 2.6$)$ ( $\mathrm{p}=0.01$ ).

Table 4 presents characteristics of men with fatal ischaemic heart disease during 11 years of follow up as estimated in a Cox proportional hazards regression analysis, including potential confounding variables associated with Le (a-b-), BMI, triglycerides, and the classical risk factors for ischaemic heart disease. A multiplicative interaction term consisting of two dichotomous variables- Le $(a-b-)$ coded 1 , others coded 0 - and low and high leisure time physical activity level coded correspondingly, significantly separated the men who suffered a fatal ischaemic heart disease event from the others $(p<0.001)$. Five other risk factors also remained in the model after multivariable adjustment: age $(\mathrm{p}=0.001)$; hypertension $(\mathrm{p}<0.05)$; triglyceride risk level 1.6$2.5 \mathrm{mmol} / 1 \quad(\mathrm{p}<0.05)$; LDL cholesterol $(\mathrm{p}<0.05)$; and systolic blood pressure $(\mathrm{p}<0.05)$.

Finally, we calculated the attributable risk of fatal ischaemic heart disease associated with $\mathrm{Le}(\mathrm{a}-\mathrm{b}-)$. In the group of physically inactive men, as a point estimate $12 \%$ of all fatal ischaemic heart disease events could be ascribed to the excess risk in $\mathrm{Le}(\mathrm{a}-\mathrm{b}-)$ men. In men with a high leisure time physical activity only $2 \%$ of fatal ischaemic heart disease cases could be attributed to the presence of the genetic high risk Le $(a-b-)$ phenotype.

\section{Discussion}

In this study we showed there was a significant interaction between the genetic marker 
Le $(a-b-)$, low leisure time physical activity, and the risk of fatal ischaemic heart disease, indicating that $\mathrm{Le}(\mathrm{a}-\mathrm{b}-)$ is a stronger risk factor in sedentary men than in men who are more physically active. This finding suggests that physical activity may be an even more valuable protector against ischaemic heart disease in $\operatorname{Le}(\mathrm{a}-\mathrm{b}-)$ men than in men with other phenotypes. In addition, our results emphasise the importance of taking lifestyle into account in studies of genetic susceptibility and risk.

Could our finding reflect bias from genetic selection or from the Lewis typing itself? This seems unlikely. The distribution of Lewis phenotypes in our study was in agreement with previous studies of Danes. ${ }^{35}{ }^{36}$ With the technique used, a few men determined as having Lewis phenotype $(\mathrm{a}-\mathrm{b}-)$ might have been classified as $\operatorname{Le}(a+b-)$ or $\operatorname{Le}(a-b+)$ if we had used genotyping $^{37}$; however, such a misclassification would only have the effect of a minor weakening of the strength of our findings. Lack of bias in this respect, and comprehensive control of confounding variables, including classical risk factors, further supports the view that our finding is not spurious-assuming that a biologically plausible explanation can be established.

What pathogenic pathway might be responsible for the increased risk of ischaemic heart disease among Le $(a-b-)$ men? The interaction between Lewis phenotypes, leisure time physical activity, and the risk of fatal ischaemic heart disease was not explained by underlying differences between $\operatorname{Le}(\mathrm{a}-\mathrm{b}-)$ men and others with respect to triglyceride or BMI (table 4). Only a few other studies have compared ischaemic heart disease risk factors and the risk characteristics of $\operatorname{Le}(a-b-)$ men with those of others. A recent US cross sectional study by Ellison and colleagues found a higher triglyceride concentration and a doubled odds ratio for ischaemic heart disease among $\operatorname{Le}(\mathrm{a}-\mathrm{b}-)$ men; the increased risk was not explained by triglyceride differences or by other conventional ischaemic heart disease risk factors, and consequently $\mathrm{Le}(\mathrm{a}-\mathrm{b}-)$ was suggested to be "an independent risk factor of ischaemic heart disease" ; considering that no linkage analyses of chromosome 19 have shown a linkage between the Lewis locus and other genetic markers of ischaemic heart disease risk, the authors may be right. A Danish cross sectional study of young men aged 18-31 years showed that $\mathrm{Le}(\mathrm{a}-\mathrm{b}-)$ men had significantly higher BMI, systolic blood pressure, and fasting concentrations of serum insulin and plasma glucose. ${ }^{9}$ In a French population, Petit and colleagues found no adverse risk factor distribution between $\operatorname{Le}(\mathrm{a}-\mathrm{b}-)$ and others, only a nonsignificantly increased triglyceride concentration..$^{38}$ In a French clinical study the investigators found a significantly increased proportion of $\mathrm{Le}(\mathrm{a}-\mathrm{b}-)$ among patients with NIDDM (mean age 63.5 years) compared with healthy age matched controls. ${ }^{39}$ The occurrence of ischaemic heart disease was not reported in the latter studies. ${ }^{9}{ }^{38}{ }^{39}$ Green and colleagues have found an association between several clotting factors and the $\operatorname{Le}(\mathrm{a}-\mathrm{b}-)$ phenotype ${ }^{40}$; how- ever, they found a very high proportion of $\mathrm{Le}(\mathrm{a}-\mathrm{b}-)$ men among white subjects $(22 \%)$, and the validity of the Lewis typing in their study has been questioned. ${ }^{41}$ Accordingly, several risk factors may constitute the pathogenic pathway of the increased risk of ischaemic heart disease in $\operatorname{Le}(a-b-)$ men. Further research is called for. ${ }^{42}$

In a previous paper from the British regional heart study, Wannamethee and associates addressed the issue of who dies in a heart attack. ${ }^{43}$ A low level of physical activity was associated with a high risk of case fatality, and a moderate level of alcohol consumption was associated with a significantly reduced case fatality. In the Copenhagen male study, $\mathrm{Le}(\mathrm{a}-\mathrm{b}-)$ men are more prone to die of a heart attack than men with other Lewis phenotypes. ${ }^{3}$ It is interesting in the light of Wannamethee's findings that a low level of physical activity is associated with a particularly high risk of dying from ischaemic heart disease in $\operatorname{Le}(a-b-)$ men, and that moderate alcohol consumption seems to be more protective in $\operatorname{Le}(a-b-)$ men than in others. ${ }^{5}$ Could the underlying Lewis phenotype distribution contribute to the explanation of the findings in the British regional heart study?

\section{CONCLUSIONS}

The excess risk of fatal ischaemic heart disease in middle aged and elderly men with the $\mathrm{Le}(\mathrm{a}-\mathrm{b}-)$ phenotype is strongly modified by leisure time physical activity, emphasising the importance of taking into account lifestyle in studies of genetic susceptibility and risk. The public health and clinical implications may be particularly important in populations with a predominantly sedentary lifestyle and a high proportion of $\operatorname{Le}(a-b-)$ men.

This study received grants from the King Christian X's Foundation, the Danish Medical Research Council, the Danish Heart Foundation, and the Else and Mogens WedellWedellsborg Foundation.

1 Henry S, Oriol R, Samuelsson B. Lewis histo-blood group system and associated secretory phenotypes. Vox Sang 1995;69:166-82.

2 Oriol R, Le Pendu J, Mollicone R, et al. Genetic regulation of the expression of $\mathrm{ABH}$ and Lewis antigens in tissues. APMIS Suppl 1992;100:28-38.

3 Hein HO, Sørensen H, Suadicani P, et al. The Lewis blood group - a new genetic marker of ischemic heart disease. $\mathcal{F}$ Intern Med 1992;232:481-7.

4 Ellison RC, Zhang Y, Myers RH, et al. Lewis blood group phenotype as an independent risk factor for coronary heart disease. The NHLBI Family Heart Study. Am $\mathcal{F}$ Cardiol 1999;83:345-8.

5 Hein HO, Suadicani P, Sørensen H, et al. Alcohol consumption, Lewis phenotypes, and risk of ischaemic heart disease. Lancet 1993;341:392-6.

6 Meeran K, Bloom SR. Lewis phenotypes, insulin resistance, and risk of ischaemic heart disease (editorial). Br Heart $\mathcal{f}$ and risk of ischa.

7 Chaudhary R, Shukla JS. Association of Lewis blood group with ischaemic heart disease. Indian f Med Res 1999;109: 103-4.

8 Mourant AE, Kopec AC, Damaniewska-Sobczak K. The distribution of the human blood groups and other polymorphisms. Oxford: Oxford University Press, 1976

9 Clausen J, Hein HO, Suadicani P, et al. Lewis phenotypes and the insulin resistance syndrome in young healthy white men and woman. Am ₹ Hypertens 1995;8:1060-6.

10 Thune I, Njolstad I, Lochen ML, et al. Physical activity improves the metabolic risk profiles in men and women: the Tromsø Study. Arch Intern Med 1998;158:1633-40.

11 Mitchell HW, Blair SN. Epidemiology of physical activity, physical fitness and coronary heart disease. $\mathcal{F}$ Cardiovascular Risk 1995;2:289-95.

12 Hein HO, Suadicani P, Gyntelberg F. Physical fitness or physical activity in leisure time as predictors of ischaemic heart disease. F Intern Med 1992;232:471-80. 
13 Hein HO, Suadicani P, Sørensen H, et al. Changes in physical activity level and risk of ischeemic heart disease. Scand cal activity level and risk of isch
$\mathcal{M}$ Med Sci Sports $1994 ; 4: 57-64$

14 Paffenbarger RS, Hyde RT, Wing AL, et al. The association of changes in physical activity level and other lifestyle characteristics with mortality among men. $N$ Engl f Med 1993; 328:538-45.

15 Blair SN, Cooper KH, Gibbons LW, et al. Changes in coronary heart disease risk factors associated with increased treadmill time in 753 men. Am $\mathcal{F}$ Epidemio 1983;118:352-9.

16 Fletcher GF, Balady G, Blair SN, et al. Statement on exercise: benefits and recommendations for physical activity. Programs for all Americans. Circulation 1996;94:85762 .

17 Gyntelberg F. Physical fitness and coronary heart disease in male residents in Copenhagen aged 40-59. Dan Med Bull 1973;20:1-4.

18 Suadicani P, Hein HO, Gyntelberg F. Serum cotinine validated form of smoking does not account for social inequalities in risk of ischaemic heart disease: the inequalities in risk of ischaemic heart disease: the Copenhagen Male Study

19 Storm HH, Michelsen EV, Clemmensen IH, et al. The Danish Cancer Registry - history, content, quality and use. Dan Med Bull 1997; 44:535-9.

20 Siedel J, Klose S, Ziegenhorn J, et al. Improved reagent for the determination of serum cholesterol. I Clin Chem Biochem 1981;19:838-9.

21 Stahler F, Gruber W, Stinshoff K, et al. Eine praxis gerechte enzymatische Cholesterin-Bestimmung. Med Lab 1977;30 29-37.

22 Burstein M, Scholnick HR, Morfin R. Rapid method for the isolation of lipoproteins from human serum by precipitation with polyanions. Lipid Res 1970;11:583-95.

23 Lopes-Virella, MF. Cholesterol determination in highdensity lipoproteins separated by three different methods. density lipoproteins separated
Clin $1977 ; 23: 882-4$

24 Jeppesen J, Hein HO, Suadicani P, et al. Triglyceride concentration and ischaemic heart disease: an eight year
follow-up in the Copenhagen Male Study. Circulation follow-up in the

25 Friedewald WT, Levy J, Friedrickson DS. Estimation of the concentration of low-density-lipoprotein cholesterol in plasma, without use of the preparative ultracentrifuge. Clin Chem 1972;18:499-509.

26 Rose GA, Holland WW, Crowley EA. A sphygmomanometer for epidemiologists. Lancet 1964;i:296-300

27 Rose GA, Blackburn H, Gillum RF, et al. Cardiovascular survey methods, 2nd ed. Geneva: World Health Organisation, 1982 .
28 Svalastoga K. Prestige, class and mobility. Copenhagen: Munksgaard, 1959.

29 Juel K, Helweg-Larsen K. The Danish registers of causes of death. Dan Med Bull 1999;46:354-7.

30 Andersen TF, Madsen M, Jørgensen J, et al. The Danish national hospital register. A valuable source of data for modern health sciences. Dan Med Bull 1999;46:263-8.

31 Cox DR. Regression models and life-tables. F R Stat Soc 1972;34:187-220

32 Kleinbaum DG, Kupper LL, Morgenstern H. Epidemiological research. Principles and quantitative methods. London: Lifetime Learning Publications, 1982: chapter 19.

33 Norusis MJ. SPSS for Windows: base system users guide. Release 6.0. Chicago: SPSS Inc, 1994.

34 Norusis MJ. SPSS for Windows: advanced statistics. Release 6.1. Chicago: SPSS Inc, 1994.

35 Skov F, Eriksen M, Hagerup L. Distribution of the ABO, MNS, P, rhesus, Lutheran, Kell, Lewis, and Duffy blood groups and frequency of irregular red cell antibodies in a population of Danes aged fifty years and a population of population of Danes aged fifty years and a population of 1970;section B78:553-9.

36 Gürtler H. Blood group distribution and genetical structure of the Danish population. Bull Eur Soc Hum Genet 1974;8: 27-47a.

37 Vestergaard EM, Hein $\mathrm{HO}$, Meyer $\mathrm{H}$, et al. Reference values and biological variation for tumor marker CA 19-9 in serum for different Lewis and secretor genotypes and evaluation of secretor and Lewis genotyping in a Caucasian population. Clin Chem 1999;45:54-61.

38 Petit JM, Morvan Y, Viviani V, et al. Insulin resistance syndrome and Lewis phenotype in healthy men and women. Horm Metab Res 1997;29:193-5.

39 Petit JM, Morvan Y, Mansuy-Collignon S, et al. Hypertriglyceridemia in Lewis(a-b-) phenotype in non-insulindependent diabetic patients. Diabetes Metab 1997;23:2024.

40 Green D, Jarrett O, Ruth KJ, et al. Relationship among Lewis phenotype, clotting factors, and other cardiovascular risk factors in young adults. F Clin Med 1995;125:334-9.

41 Swanson JL, McCullough J. Lewis phenotypes [letter]. $\mathcal{F}$ Clin Med 1996;127:104.

42 Greenwell P. Blood group antigens: molecules seeking a function? Glycoconj f 1997; 14:159-73.

43 Wannamethee G, Whincup PH, Shaper AG, et al. Factors determining case fatality in myocardial infarction: "Who dies in a heart attack?" Br Heart 7 1995;74:324-31. 